\title{
A Development Density Allocation Model based on Environmental Carrying Capacity
}

\author{
Dongwoo Lee and Kyushik Oh
}

\begin{abstract}
This study developed a development density allocation model for sustainable urban development based on environmental carrying capacity theory and ubiquitous technology. The environmental standard of $\mathrm{NO}_{2}$ was used as the indicator to calculate the largest development density because it is a crucial air pollutant source in Korea. The process of allocating development densities consisted of 3 steps; trajectory analysis, air pollutants dispersion analysis, and development densities allocation. First, trajectory analysis was applied to pre-development conditions such as emission volume and locations. The additional pollutants emission volume caused by new urban development was inputted to employ the air pollutants dispersion model. Secondly, the air pollutants dispersion model was used to identify concentrations of air pollutants dispersed by the additional pollutants. Comparing air pollutant concentrations with environmental standards, the suitable population density of the development area was calculated. Finally, population density was allocated based on the results of the pollutants dispersion analysis. The results of the development density allocation model can be useful for preparing density and land-use maps in planning processes.
\end{abstract}

Index Terms-Environmental carrying capacity, development density, ubiquitous technology.

\section{INTRODUCTION}

Urban development density has been traditionally estimated based on the developable area unit and plan population unit. Moreover, development density allocation has been determined typically by planners' professional experiences and decisions. Because determining development density is the basis of urban planning, development density allocation based on uncertainty can cause unsuitableness of planning components such land use and urban design, transportation, and so on. Therefore, estimating urban development density and allocation is the primary condition for achieving sustainable urban planning and management.

In this regard, combining the carrying capacity concept with ubiquitous technology, this study established the development density allocation model in order to construct an environmentally sustainable city. The environmental carrying capacity concept in this study refers to the management of pollution under a permissible level through urban planning and management. Based on this concept, this study established the development density allocation model to estimate suitable development density. To test the

Manuscript received September 13, 2012; revised October 25, 2012.

The authors are with Department of Urban Planning, Hanyang University, 222 Wangsimni-ro, Seongdong-gu, Seoul, Korea (e-mail:estevan97@hanyang.ac.kr; ksoh@hanyang.ac.kr). usefulness of the developed model, a case study was conducted in a real urban development project area in Korea.

\section{LITERATURE REVIEW}

\section{A. Environmental Carrying Capacity}

The concept of environmental carrying capacity has been studied and applied in the fields of ecology, tourism, urban planning, and environmental planning since the 1930s. The concepts of carrying capacity are based on the assumption that there are certain environmental thresholds that when exceeded can cause serious and irreversible damage to the natural environment [1]. In terms of urban planning, carrying capacity is the determined ability of the natural and artificial environments to support the demands of various uses [2]. In addition, carrying capacity is defined as the ability of natural and human-made systems to absorb population growth or physical development without serious decline or damage. Carton (1987) suggested three types of sustainable loads based on environmental carrying capacity (see Fig. 1). To sum it up, the urban carrying capacity concept is defined as the level of human activities that can be sustained by the environment without causing degradation or irreversible damage [3].
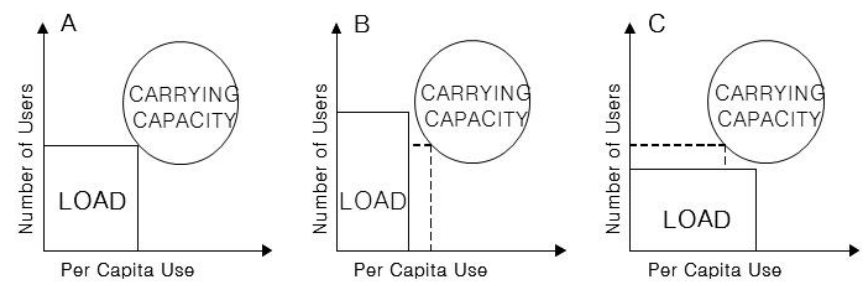

Fig. 1. Three types of sustainable loads [4]

\section{B. Ubiquitous Technologies in Urban Spaces}

Recently, there have been some efforts to adopt ubiquitous technologies to urban spaces. 'Ubiquitous' is a Latin word that is used to refer to the information or communication environment in which freely connected computer networks exist like water or air without others sensing them. This term initially appeared in the phrase 'ubiquitous computing' used by Mark Weiser at Xerox laboratories in 1988 [5]-[6]. Thus, a ubiquitous city refers to the use of ubiquitous technology in urban spaces. This is currently an active and vibrant research subject in urban study fields.

Concrete and practice research on the ubiquitous city have been studied in Korea. Subsequently, various planning methods, acts, and standards such as the 'Ubiquitous City Comprehensive Plan', 'Ubiquitous City Construction Act', 
and 'Ubiquitous City Technology Standards' have been established. Actual urban development projects have been planned to realize the ubiquitous city, and progress is underway. Among these projects is the Ubiquitous-Ecological City (U-Eco City), which is a combination of the ecological city that focuses on monitoring and managing of the various environmental aspects of an urban space [7]. In the U-Eco City, various types of environmental information are measured in real time and are in turn applied for more efficient urban management. This can lead to innovations in urban planning and management, particularly in the area of the urban environment, through the resolution of problems such as a lack of environmental information and the absence of accumulated data [8].

\section{DeVelopment Density Allocation Model}

In order to assess carrying capacity, environmental elements such as air and water quality are considered primary elements [9]-[10]. Air and water qualities are essential elements to sustain the basic environmental level of human beings and are important indices to assess carrying capacity [8]. In this study, air quality $\left(\mathrm{NO}_{2}\right)$ was adopted to calculate development density because it is a crucial air pollutant source in urban areas. The allocating development density process consists of survey/measuring environmental information, determining development density, and allocating development density (see Fig. 2).

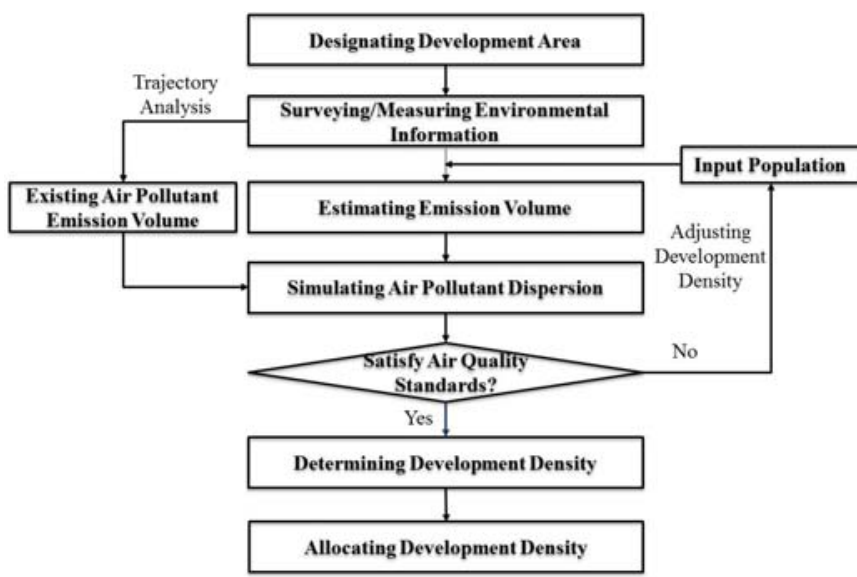

Fig. 2. Allocating development density process

Surveying/Measuring Environmental Information Environmental information measurement is a process to monitor various types of environmental information that are gathered in real-time. The information are saved in an environmental Data Base (DB) and used as basic means to assess ecological value and to calculate development density. To obtain environmental information, sensing equipment developed by Korea Telecom (KT) was used (see Fig. 3).

There are 2 types of Ubiquitous Sensors: one is a moveable sensor box and the other one is a fixed sensor box. The latter was installed permanently at one location and measured environmental information continuously. The moveable sensor box was set up where environmental problems occur or additional information was needed, including air quality $\left(\mathrm{CO}_{2}, \mathrm{NO}_{2}, \mathrm{PMx}\right)$ and weather conditions (temperature, humidity, wind speed and direction).

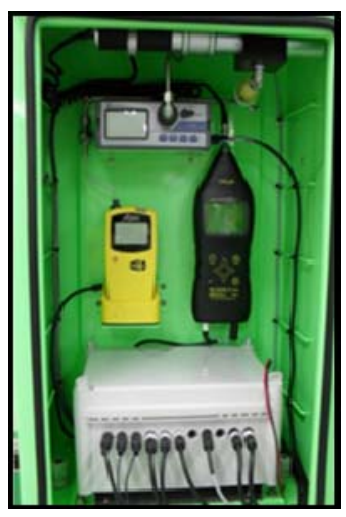

(a) Moveable Sensor Box

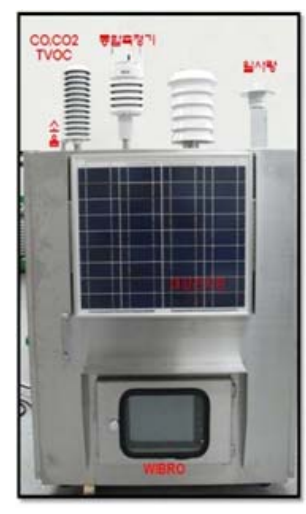

(b) Fixed Sensor Box
Fig. 3. Sensing equipment developed by Korea Telecom (KT)

\section{A. Determining Development Density}

Carrying capacity is used to suggest the development limit that serves to prevent environmental overload. In this study, air quality $\left(\mathrm{NO}_{2}\right)$ was used as the indicator to determine suitable development density. The process to calculate development density consisted of 2 steps; trajectory analysis and the air pollutants dispersion analysis.

The trajectory model estimated locations and volumes of pollutant emissions from the air pollutant concentrations with consideration to the terrain, weather conditions, and land-cover. The results of the trajectory analysis revealed already existing emission volumes and locations that can affect the development area.

The air pollutant dispersion model calculated the concentrations of air pollutants dispersed by the pollutants with consideration to terrain, buildings, and weather conditions. The additional emission volume caused by development was inputted to estimate suitable development density. The additional air pollutant emission volume was calculated by an emission coefficient of a person in the emission statistical data. The additional pollutants emission volume was distributed where developments are permitted. The air pollutant concentration derived from the dispersion model was compared to environmental standards. If it exceeded the standard, the inputted population had to be decreased. On the contrary, if the concentration of the pollutants was below environmental standards, a higher concentration of population would have to be assigned to the development area.

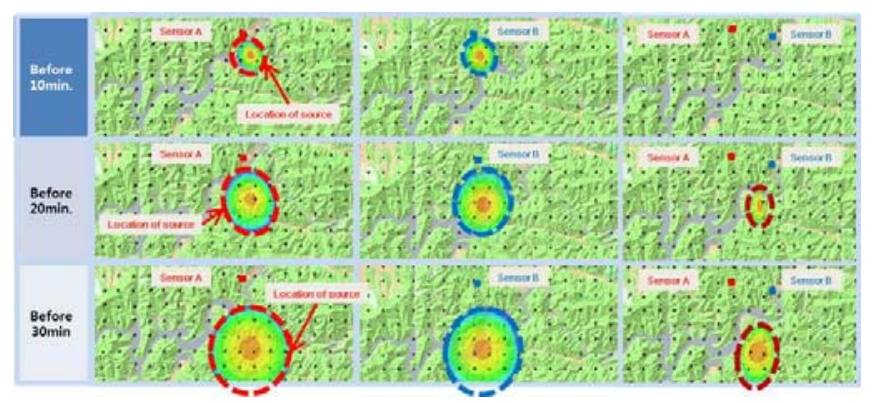

Fig. 4. Concept of trajectory model 

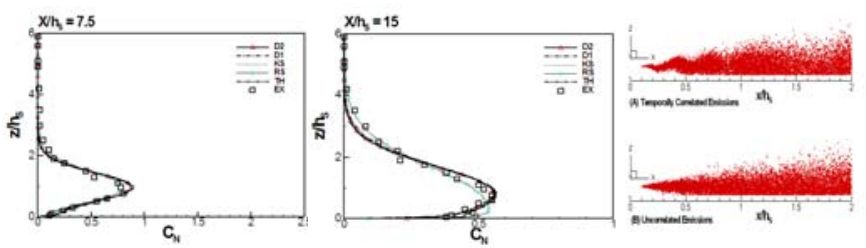

Fig. 5. Concept of air pollutant dispersion model

\section{B. Allocating Development Density}

Allocating development density involves suggesting detailed guidelines for the next plan phase which meets the environmental permissible level and protects conservation areas. Development density can be allocated discriminately based on the air pollutant dispersion model results and landscape ecology theory. There are some areas that exceed environmental standards because development density was estimated by average pollutant concentration. Therefore, the pollutant concentration coefficient of a person was calculated by analyzing the relationship of pollutant concentration with the estimated development density. The development density was allocated by comparing environmental standards. In the area exceeding environmental standards, less development density was allocated based on the pollutant concentration coefficient of a person. On the contrary, if the concentration of the pollutant was below environmental standards, additional development density was allocated.

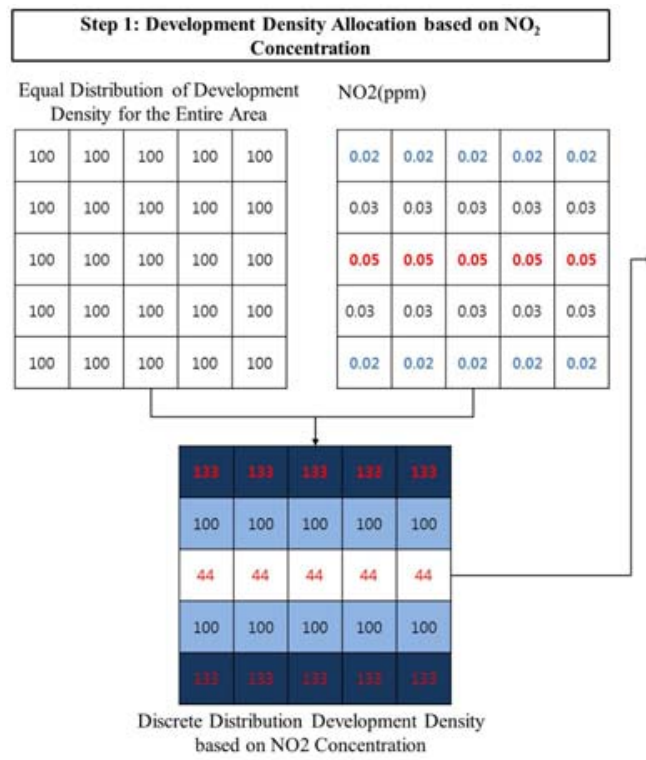

From a landscape ecology perspective, forest edge areas have various functions for sustaining ecological value [11]. In this study, the areas within 30 meters from conservation areas were additionally determined to be conservation areas to protect the edge of the conservation areas. Considering this rule, two types of developable areas are suggested; neighboring areas with the conservation areas, and net developable areas. The lesser development density was allocated to the neighboring areas of the conservation areas. The decreased development density in neighboring areas of the conservation areas was additionally allocated in net developable areas (see Table I).

TABLE I: ALLOCATING DEVELOPMENT DENSITY STANDARDS WITH CONSIDERATION TO THE CONSERVATION AREA

\begin{tabular}{c|c|c}
\hline \hline \multicolumn{2}{c|}{ Classification } & Development Allocation Standards \\
\hline \multirow{2}{*}{$\begin{array}{c}\text { Conservation areas } \\
\text { Developable } \\
\text { areas }\end{array}$} & $\begin{array}{c}\text { Neighboring areas } \\
\text { of the conservation } \\
\text { areas }\end{array}$ & $\begin{array}{c}\text { Not allocating development density } \\
\text { considering conservation areas }\end{array}$ \\
\cline { 2 - 3 } & $\begin{array}{c}\text { Net developable } \\
\text { areas }\end{array}$ & $\begin{array}{c}\text { Development density based on the } \\
\text { pollutant concentration coefficient + } \\
\text { decreased development density in } \\
\text { neighboring areas of conservation } \\
\text { areas }\end{array}$ \\
\hline \hline
\end{tabular}

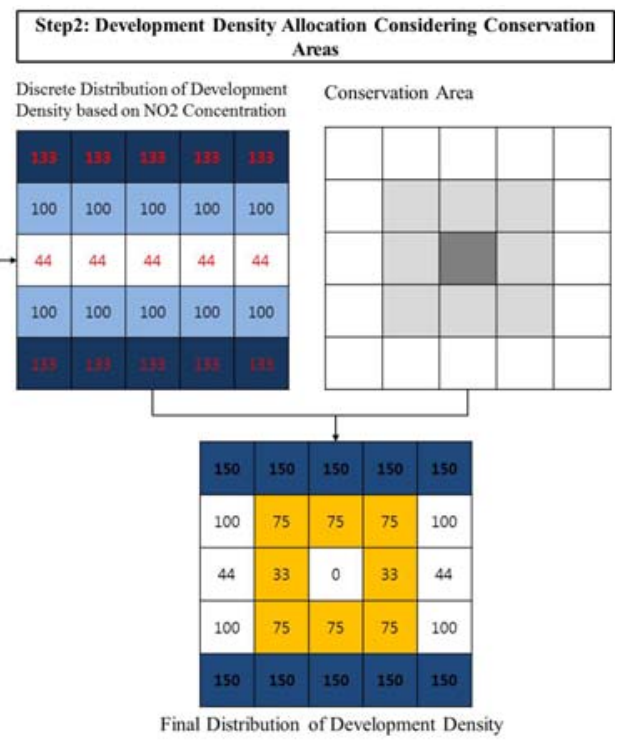

Fig. 6. Development density allocation based on $\mathrm{NO}_{2}$ dispersion and conservation areas

\section{CASE StUdy}

\section{A. The Study Area}

The study area is located in the southwestern part of Seoul, the capital city of Korea. The total area of the study area is approximately 1,737ha and currently in the process of new town development with 95,000 households. Currently, the main study area is being used for agricultural purposes. The development density of the case study area is about 164.1 persons/ha and about $20 \%$ of study area is planned as a conservation area (see Fig. 7).
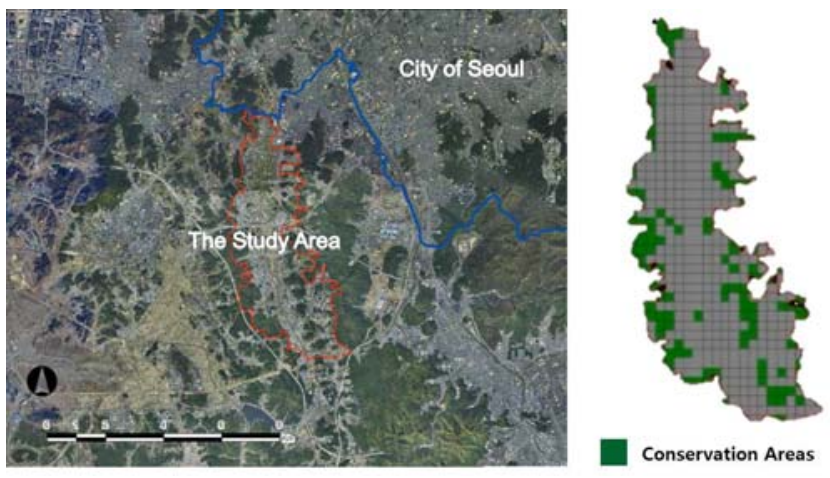

Fig. 7. The study area 


\section{B. Development Density Calculation}

The emission unit of the $\mathrm{NO}_{2}$ pollutant, $13.4 \mathrm{~kg}$ per person a year suggested by the National Institute of Environmental Research, Korea (NIER), was used in estimating additional emission volume by urban development. Next, an air pollutant dispersion simulation was executed, and the average concentration was compared with environmental permissible standards to determine the suitable development density. The air pollutant dispersion model results showed that the center area has a relatively high concentration because an urban express highway crosses the center of the study area. The air pollutant dispersion simulation was iterated 4 times to find the development density. As a result, it was found that a development density of 113 persons/ha is suitable in meeting environmental standards (see Fig. 8 and Table II). The calculated development density is a little lower than the density of a low density city according to Korean development density standards. Otherwise, it is a little higher than environmental-ecological city standards. To meet environmental standards, 51 persons/ha should be adjusted in the current plan (see Table III).

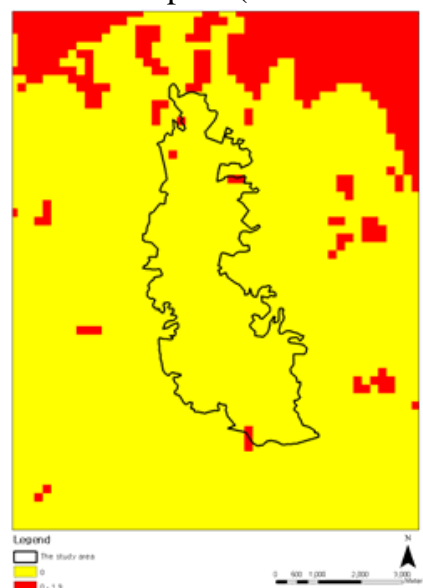

(a) Estimated air pollutant emission (g / hour)

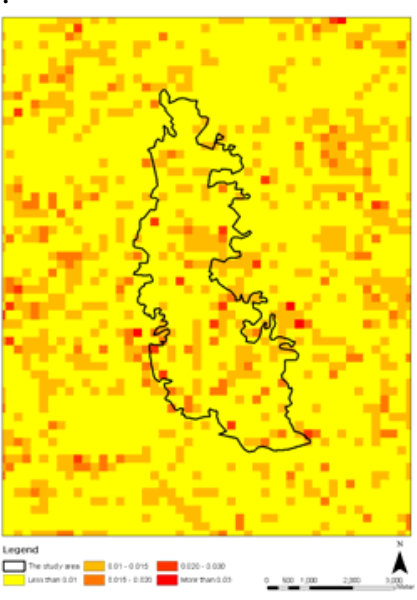

(b) NO2 concentration (ppm) for 113 persons/h
TABLE II: RESULTS OF THE AIR POLLUTANT DISPERSION MODEL

\begin{tabular}{c|c|c|c|c|c}
\hline \hline Classification & $\begin{array}{c}\text { Iteration } \\
1\end{array}$ & $\begin{array}{c}\text { Iteration } \\
2\end{array}$ & $\begin{array}{c}\text { Iteration } \\
3\end{array}$ & $\begin{array}{c}\text { Iteration } \\
4\end{array}$ & $\begin{array}{c}\text { Development } \\
\text { density }\end{array}$ \\
\hline $\begin{array}{c}\text { Population } \\
\text { Density } \\
\text { (persons/ha) }\end{array}$ & 200 & 100 & 150 & 125 & 113 \\
\hline $\begin{array}{c}\text { Average } \\
\text { (ppm) }\end{array}$ & 0.0310 & 0.0291 & 0.0297 & 0.0303 & 0.030 \\
\hline $\begin{array}{c}\text { Maximum } \\
(\mathrm{ppm})\end{array}$ & 0.0336 & 0.0305 & 0.0307 & 0.0315 & 0.304 \\
\hline $\begin{array}{c}\text { Minimum } \\
(\mathrm{ppm})\end{array}$ & 0.0279 & 0.0278 & 0.0278 & 0.0278 & 0.0278 \\
\hline \hline
\end{tabular}

TABLE III: COMPARISON OF THE STUDY RESULTS WITH GENERAL DEVELOPMENT DENSITIES USED IN KOREA [12]

\begin{tabular}{c|c|c}
\hline \hline \multirow{2}{*}{ Classification } & Development density (Persons/ha) \\
\hline \multirow{2}{*}{ The cases study } & Original plan & 164 \\
\cline { 2 - 3 } & Study result & 113 \\
\hline \multicolumn{2}{c}{ Eco friendly development } & 100 \\
\hline \multicolumn{2}{c}{ Low density development } & 125 \\
\hline
\end{tabular}

\section{Development Density Allocation}

Fig. 9 shows the results of allocating development density. Development density was not allocated in conservation areas. The relatively low development density was allocated in areas near conservation areas. Low development density was also allocated near an urban express highway because of the high concentration. As a result, relatively high development is available in the northern and southern areas.

Fig. 8. Results of trajectory analysis and the air pollutant dispersion model

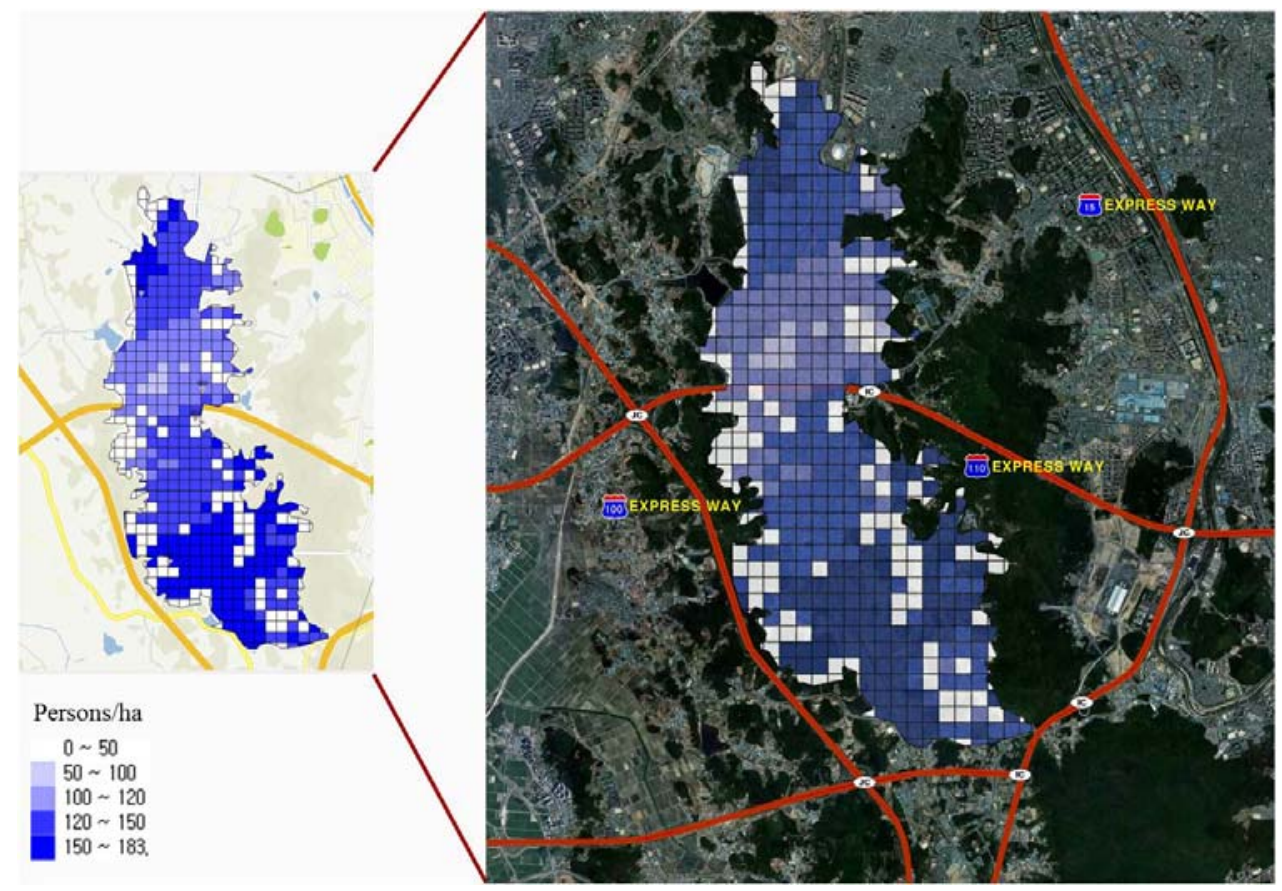

Fig. 9. Results of development density allocation 
To compare with equal development density, the air dispersion model was conducted based on emission of the allocated development density. The maximum, average NO2 concentration by development density allocation result was lower than the result of before the statue, because the emission volume was dispersed in low $\mathrm{NO}_{2}$ concentration areas. However minimum $\mathrm{NO}_{2}$ was increased a little because additional emission was added in low NO2 concentration areas (See Table IV).

TABLE IV: COMPARISON OF THE EQUAL DEVELOPMENT DENSITY RESULTS WITH DEVELOPMENT DENSITY ALLOCATION RESULTS

\begin{tabular}{c|c|c}
\hline \multicolumn{2}{c|}{ WITH DEVELOPMENT DENSITY ALLOCATION RESULTS } \\
\hline Classification & $\begin{array}{c}\text { Before allocation } \\
\left(\mathrm{NO}_{2}\right)\end{array}$ & $\begin{array}{c}\text { After allocation } \\
\left(\mathrm{NO}_{2}\right)\end{array}$ \\
\hline $\begin{array}{c}\text { Population Density } \\
\text { (persons/ha) }\end{array}$ & 113 & 113 \\
\hline Average (ppm) & 0.030 & 0.029 \\
\hline Maximum (ppm) & 0.304 & 0.301 \\
\hline Minimum (ppm) & 0.027 & 0.028 \\
\hline \hline
\end{tabular}

\section{CONCLUSION}

Estimating urban development density and allocation is the primary condition to achieve sustainable urban planning and management. Ubiquitous technology can also lead to innovations in urban planning and management. In this study, the development density allocation model was developed as a tool for urban development and management in the U-Eco City.

Quantitative urban development density meets the environmentally permissible level estimated quantitatively, and it was allocated based on the air pollutant dispersion modeling results. The findings of this study are clear and can be usefully adopted in policymaking and in the planning process because development densities such as population, density, etc., are suggested. Moreover, the results of the development density allocation model can be used as a guideline for more detailed plans or urban designs.

Combining the carrying capacity concept with ubiquitous technology, this study attempts to establish a scientific and logical foundation to estimate suitable development density which is the primary condition for achieving sustainable urban planning and management. The estimation of development density based on scientific and logical methods will decrease the uncertainty in planning, and will also lead to a paradigm shift in urban planning fields.

Nevertheless, improvement of the model is needed due to its use of limited data of $\mathrm{NO}_{2}$ to calculate development density. For more accurate assessment, other factors that influence development density should be considered. In addition, more usefulness of the system can be determined once social and economical factors are considered in the development density allocation model.

\section{ACKNOWLEDGMENT}

This research was supported by a grant (07High Tech A01) from the High Tech Urban Development Program funded by the Ministry of Land, Transportation and Maritime Affairs of the Korean government.

\section{REFERENCES}

[1] J. Kozlowski, "Sustainable development in professional planning: a potential contribution of the EIA and UET concepts," Landscape and Urban Planning, vol.19, issues 4, pp.307-332, 1990.

[2] D. Schneider, D. Godschalk, and N. Axler, " The carrying capacity concept as a planning tool,” Journal of American Planning Association, 1978.

[3] K. Oh, Y. Jeong, D. Lee, W. Lee and J. Choi, "Determining development density using the Urban Carrying Capacity Assessment System,” Landscape and Urban Planning vol. 73, issues 1, pp. 1-15, 2005.

[4] W. R. Catton, "The world's most polymorphic species: carrying capacity transgressed two ways," Bioscience, vol. 37, pp. 413-419, 1987.

[5] M. Weiser, "The Computer for the Twenty-first Century," Scientific American, vol. 265, issues 3, pp. 94-104, 1991.

[6] M. Weiser, “The World is not a Desktop,” Interactions, vol.1, issues 1, pp. 7-8, 1994.

[7] K. Jeong, "Implementation Strategies for future ubiquitous cities based on U-city service model,” Entrue Kournal of Information Technology vol. 6, issues 1, pp. 81-100, 2007

[8] S. Lee and K. Oh, "Environmental-ecological Analysis SYStem (EASYS) for Urban Planning," Proceeding of 3rd International Conference on Environmental Science and Development, 2012.

[9] D. Godschalk and F. Parker, "Carrying capacity: a key to environmental planning,” Journal of Soil and Water Conservation vol. 30, issues 4, pp.160-165, 1975.

[10] S. Chung, "A Conceptual model for regional environmental planning centered on carrying capacity measures," The Korean Journal of Regional Science, vol. 4, issues 2, pp. 117-128, 1988.

[11] R.T.T. Forman, Land mosaics: The ecology of landscape and regions. New York: Cambridge University Press, 1988.

KLC, Ecological City Development Handbook, Korea Land Cooperation, Korea, 2005. 